\title{
Design and experiment of centralized pneumatic deep precision fertilization device for rice transplanter
}

\author{
Xiantao Zha ${ }^{1,2}$, Guozhong Zhang ${ }^{1,2 *}$, Shijie Zhang ${ }^{1,2}$, Qunxi $\mathrm{Hou}^{1,2}$, Yang Wang ${ }^{1,2}$, Yong Zhou ${ }^{1,2}$ \\ (1. College of Engineering, Huazhong Agricultural University, Wuhan 430070, China; \\ 2. Key Laboratory of Agricultural Equipment in Mid-lower Yangtze River, Ministry of Agriculture and Rural Affairs, Wuhan 430070, China)
}

\begin{abstract}
To improve the precision of deep fertilization of paddy fields, a six-row centralized pneumatic deep precision fertilization device for a rice transplanter was designed. This device included a spiral fertilizer distribution system, centralized pneumatic fertilizer delivery system, an opener system, and a fertilization control system. The centralized airflow distribution method was used in the fertilizer delivery system to ensure that the airflow in each fertilizer pipe was evenly distributed. The rotational speeds of the power take-off (PTO) and fertilizer shaft were measured synchronously using photoelectric sensors and matched proportionately in real-time using PID closed-loop control algorithms to achieve precise fertilization rates at each working speed of the rice transplanter. There were two key considerations in the design of the control system to ensure precise fertilization. Firstly, a photoelectric sensor was used to measure the speed of the PTO; the high rotational speed of the PTO could provide a high signal frequency and improve the precision of the measurement of the transplanter's working speed. Secondly, the fertilizer shaft speed measurement subprogram was set to sleep for a short period to reduce the vibration caused by the engine. During the tests of pneumatic fertilizer delivery system, single-factor tests on airflow distribution methods were conducted. The results showed that the coefficient of variation of the airflow speed for the centralized airflow distribution method was $1.67 \%$, which was the least among the coefficients of the three distribution methods. In the bench tests, the rotational speeds of the fertilizer shaft were set at $10 \mathrm{r} / \mathrm{min}, 20 \mathrm{r} / \mathrm{min}, 30 \mathrm{r} / \mathrm{min}$, and $40 \mathrm{r} / \mathrm{min}$. The maximum coefficient of variation of the fertilization consistency in different rows was $1.49 \%$ at the rotational speed of $20 \mathrm{r} / \mathrm{min}$. The maximum coefficient of variation of the fertilization stability was $2.86 \%$ at the rotational speed of $40 \mathrm{r} / \mathrm{min}$, while the average fertilizer amount per lap for each distributor was $26.25 \mathrm{~g} / \mathrm{r}$. The results of the dynamic fertilization tests showed that the maximum relative error of the fertilizer distribution amount was $2.00 \%$ when the target fertilizer rates were 20,30 , and 40 $\mathrm{kg} / 667 \mathrm{~m}^{2}$. The results of the field tests showed that the average relative error of the fertilization amount was $3.53 \%$, which satisfies the design standard. This research provides a reference for optimizing pneumatic fertilizer delivery systems and improving fertilization control systems and other pneumatic precision fertilizer application devices.
\end{abstract}

Keywords: agricultural machinery, deep precision fertilization, pneumatic, variable rate, transplanter, vibration elimination DOI: $10.25165 /$ j.ijabe.20201306.5479

Citation: Zha X T, Zhang G Z, Zhang S J, Hou Q X, Wang Y, Zhou Y. Design and experiment of centralized pneumatic deep precision fertilization device for rice transplanter. Int J Agric \& Biol Eng, 2020; 13(6): 109-117.

\section{Introduction}

Fertilization can significantly increase rice yield. Currently, rice production in China is still employing artificial spraying, which leads to fertilizer waste, low fertilizer utilization rate, different crop growth, and environmental pollution ${ }^{[1,2]}$. However, deep precision distribution of fertilizer can effectively solve these problems $^{[3-5]}$.

Deep precision fertilization for dry land has been widely

Received date: 2019-10-18 Accepted date: 2020-08-09

Biographies: Xiantao Zha, PhD candidate, research interests: modern agricultural equipment and information technology. Email: zhaxiantao@ 163.com; Shijie Zhang, Master candidate, research interests: modern agricultural equipment and information technology. Email: 294462474@qq.com; Qunxi Hou, Master candidate, research interests: modern agricultural equipment and information technology. Email: 390769637@qq.com; Yang Wang, Master candidate, research interests: modern agricultural equipment and information technology. Email: 1228302973@qq.com; Yong Zhou, PhD, Associate Professor, research interests: modern agricultural equipment and information technology. Email: zhyong@mail.hzau.edu.cn.

*Corresponding author: Guozhong Zhang, $\mathrm{PhD}$, Professor, research interests: modern agricultural equipment and information technology. College of Engineering, Huazhong Agricultural University, Wuhan 430070, China. Tel: +86-18672783365, Email: zhanggz@mail.hzau.edu.cn. studied and used in China. Jin et al. ${ }^{[6]}$ designed a $2 \mathrm{BFJ}-24$ wheat seeder and fertilizer sowing machine, which could realize variable sowing and deep fertilization based on GPS and prescription maps. Wang et al. ${ }^{[7]}$ designed a universal precision seeder, which could apply fertilizer to the vertical and side deep positions of seeds. Zeng et al. ${ }^{[8]}$ designed a precision rice hill-drop drilling machine for dry land with synchronous fertilizing technique to carry out side deep fertilization with rice hill-drop drilling. Zhai et al. ${ }^{[9]}$ designed a pneumatic precision drilling planter for rice budded seeds, which could apply fertilizer vertically under seeds. All the aforementioned studies focused on dry land, mainly using the weights of the fertilizers for transport. However, the strong fluidity of paddy soil makes fertilizer ditches difficult to form. Further, ditch openers can be easily blocked by mud, making the application of fertilizer to designated depth by gravity only challenging. Thus, the abovementioned studies and equipment cannot be used in paddy fields directly.

Thus, enterprises and institutes in China and other Asian countries carried out some researches on paddy field precision fertilization. Qi et al. ${ }^{[10]}$ developed key parts of paddy field pneumatic variable-rate fertilizer machine, such as fertilization wheel, mixing joint of air and fertilizer, and airflow divider box, to improve the consistency of fertilization and reduce air loss. Wang 
et al. ${ }^{[11]}$ designed an electrical drive side deep fertilization system for rice direct-seeding machine to apply fertilizer synchronously with seeding. Chen et al. ${ }^{[12]}$ designed a synchronous side deep fertilizing with rice hill-drop drilling 2BDF-3.0 machinery, which could perform ditching, ridging, seeding, deep fertilizing, and soil covering. Wang et al. ${ }^{[13]}$ designed a side deep fertilization device with adjustable blades for paddy field, which could regulate the fertilizer amount by rotating the blades to adjust the diameter of the fertilizer outlet. Wang et al. ${ }^{[14]}$ also researched key parts of side deep fertilization device, such as moto-driven external groove fertilizer wheel and pneumatic fertilizer transporter system. Zuo et al. ${ }^{[15]}$ designed a side deep precision fertilization device, which used GPS to measure the forward speed and adjusted the amount of fertilizer based on the real-time forward speed. However, the machine was set to a certain forward speed in the field tests, hence, the performance of the variable rate fertilization under variable forward speed conditions was not verified. Chen et al. ${ }^{[16]}$ designed a screw auger-type side deep fertilization device for rice transplanter, which has a complex structure and could only be used for low speed. In addition, non-Chinese companies, such as Kubota $^{[17]}$, ISEKI ${ }^{[18]}$, and Yanmar ${ }^{[19]}$ as well as Chinese companies, such as Longzhou ${ }^{[20]}$ and Yongxiang ${ }^{[21]}$, have shown interest in side deep fertilization for rice transplanter and designed a variety of side deep fertilization devices.

Pneumatic conveying method can enhance fertilizer conveying performance and solve problems in paddy field deep fertilization, such as long fertilizer pipe, bending pipeline, poor fertilizer conveying performance, poor consistency, and low precision. Currently, the most widely used structure of air-blast system involves placing a fan at the end of main air duct ${ }^{[14,15,17-19]}$; however, this system has some associated problems, such as inconsistent wind power at each branch and low conveying efficiency.

There are two types of fertilization control method in paddy field: mechanical transmission, which uses ground wheel or PTO (power take-off) to drive fertilizer distributors through mechanical transmission system; and electro-mechanical, which uses GPS $^{[15,22,23]}$, $\operatorname{radar}^{[24]}$ and Hall sensor ${ }^{[25]}$ to measure forward speed and adjust fertilizer amount based on the forward speed. Mechanical transmission systems have a complex transmission structure and are difficult to install. GPS entails considerable expenses and high hysteresis. Furthermore, it is challenging to find a reliable reference for radar speed measurement, and Hall sensors have low signal frequency.

In view of the aforementioned problems, a six-row centralized pneumatic deep precision fertilization device was designed in this study; this device consists of a spiral fertilizer distribution system, centralized pneumatic fertilizer transporting system, opener system, and fertilization control system. The centralized pneumatic method was adopted to ensure consistent airflow in each fertilizer pipe. Photoelectric sensors were used to measure rotational speed of PTO and fertilize shaft. Two speeds were matched proportionately in real-time using PID closed-loop control algorithms to achieve precise fertilization at each working speed of the rice transplanter.

\section{Deep precision fertilizer distribution device with rice transplanter}

\subsection{General structure}

The centralized pneumatic deep precision fertilization device was designed based on the Yanmar VP6D high-speed rice transplanter. Its general structure is shown in Figure 1, and its main design parameters are shown in Table 1.

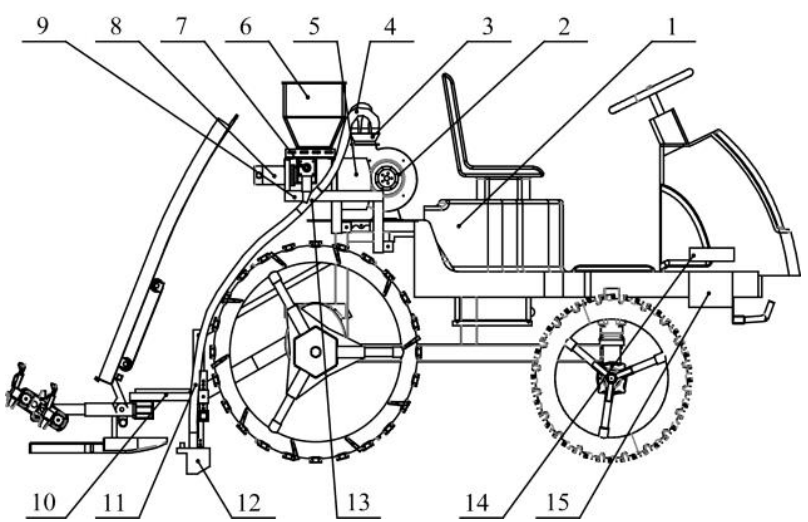

1. Yanmar VP6D transplanter 2. Centrifugal fan 3. Centralized airflow distribution device 4. Air duct 5. Motor control system 6. Fertilizer box 7. Spiral fertilizer distributor 8. Motor 9. Fertilizer distributor bracket 10. Opener fixing bracket 11. Fertilizer pipe 12. Furrow opener 13. Tee pipe 14. DC-AC inverter 15. Battery

Figure 1 Deep precision fertilizer distribution device with rice transplanter

Table 1 Main design parameters of the deep precision fertilizer distribution for rice transplanter

\begin{tabular}{|c|c|}
\hline Item & Parameter \\
\hline Machine size/mm & $3295 \times 2595 \times 2330$ \\
\hline Working width $/ \mathrm{mm}$ & 1800 \\
\hline Row spacing of transplanting $/ \mathrm{mm}$ & 300 \\
\hline Number of working rows & 6 \\
\hline Driving speed $/ \mathrm{m} \cdot \mathrm{s}^{-1}$ & $0-1.65$ \\
\hline Power of driving motor /W & 60 \\
\hline Conveying velocity $/ \mathrm{m} \cdot \mathrm{s}^{-1}$ & 20 \\
\hline Planting depth/mm & $15-60$ \\
\hline Fertilization depth/mm & $0-100$ \\
\hline Distance between fertilizer and seedling $/ \mathrm{mm}$ & $0-50$ \\
\hline Fertilization speed $/ \mathrm{kg} \cdot \mathrm{min}^{-1}$ & $0-10.20$ \\
\hline Fertilization pattern & Strip fertilization \\
\hline Total capacity of fertilizer tanks $/ \mathrm{kg}$ & 120 \\
\hline
\end{tabular}

\subsection{Operational principle}

The centralized pneumatic deep precision fertilization device was composed of four parts: spiral fertilizer distribution system, pneumatic fertilizer transporting system, furrow opener system, and fertilization control system. Its working principle was to synchronously measure the rotational speeds of PTO and fertilize shaft, feedback the rotational speed error to fertilizer control system, and adjust the rotational speed of the fertilize shaft in real time to achieve precise fertilization. The control principle is shown in Figure 2.

When the device was running, the fertilizer amount per lap of the distributor should be measured. The fertilizer amount per lap, target fertilizer discharging amount per unit area, and plant spacing were first keyed into the control system. The photoelectric sensor on the PTO obtained real-time speed while the controller used the speed of the PTO and the plant spacing to compute the forward speed of the transplanter. Then, the controller calculated the required speed of the fertilizer shaft in fertilizer amount per lap and the target fertilizer discharging amount per unit area. The PWM duty ratio was adjusted using the PID closed-loop algorithms and sent to the motor driver to regulate the real-time motor speed and control the fertilizer discharging rate. The discharged fertilizer 
was transported to the fertilizer ditch under the action of the high-speed airflow generated by the centrifugal fan and gravity. Finally, the slurry in the paddy field would flow to the fertilizer ditch and cover the fertilizer in the deep of the paddy filed.

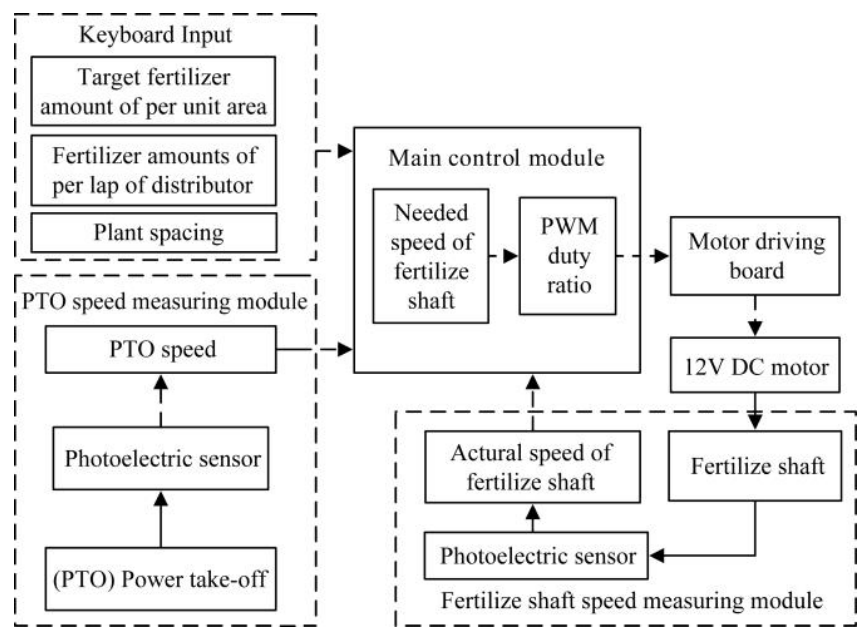

Figure 2 Principle of the fertilization control

\section{Spiral fertilizer distribution system}

\subsection{General structure}

The spiral fertilizer distribution system included spiral fertilizer distributors, fertilizer box, driving motor, and fertilizer distributor bracket. Six rows of spiral fertilizer distributors and one driving motor were installed on the chassis of the transplanter behind the seat through the bracket. Power between the fertilizer shaft and motor was transmitted through a coupling sleeve. The structure of the system is shown in Figure 3.

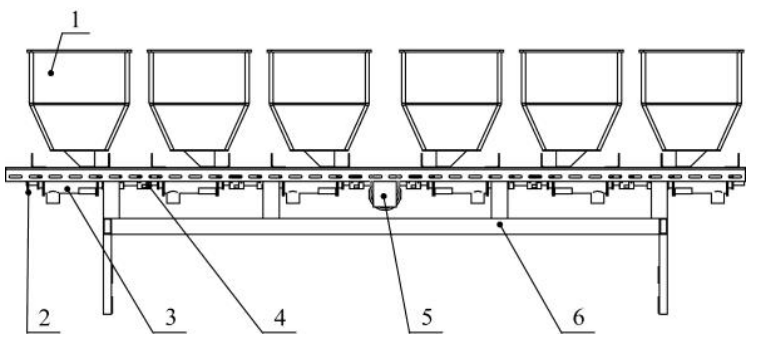

1. Fertilizer box 2. Photoelectric switch \& Circular grating disk 3. Spiral fertilizer distributor 4. Coupling sleeve 5. Motor 6. Fertilizer distributor bracket

Figure 3 Structure of the fertilizer distribution system

\subsection{Design of fertilizer dispenser}

The spiral fertilizer distributor was an important part of the fertilizer distribution system. It mainly consisted of a pyramidal feeding inlet, fertilizer transporting spiral, spiral sleeve, and outlet. Its structure is shown in Figure 4.

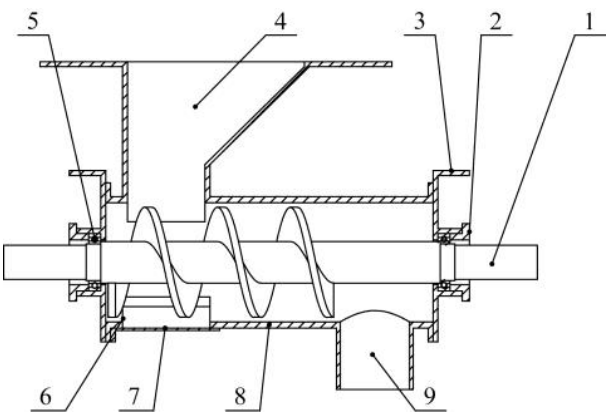

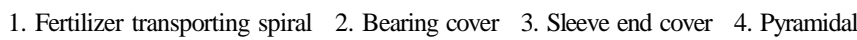
feeding inlet 5 . Bearing 6 . Fertilizer cleaning mouse 7. Fertilizer cleaning mouse cover 8 . Spiral sleeve 9 . Fertilizer outlet

Figure 4 Structure of the spiral fertilizer distributor
Generally, the machine performed transplantation and fertilization only when driving in a straight line. Thus, the applied fertilizer amount, worked area, forward speed of transplanter, fertilizer amount per lap, and rotational speed of fertilize shaft had to meet the following relationship:

$$
M=\frac{A n q}{10000 B v}
$$

where, $M$ is the applied fertilizer amount, $\mathrm{kg} ; A$ is the working area, $\mathrm{m}^{2} ; n$ is the rotating speed of fertilizer shaft, $\mathrm{r} / \mathrm{min} ; q$ is the fertilizer amount per lap of one distributor, $\mathrm{g} / \mathrm{r} ; B$ is the working width of the transplanter, $1.8 \mathrm{~m}$; and $v$ is the forward speed of the transplanter, $\mathrm{m} / \mathrm{s}$.

When the forward speed was $1.6 \mathrm{~m} / \mathrm{s}$, the target fertilization amount was $40 \mathrm{~kg} / 667 \mathrm{~m}^{2}$ and the speed of the fertilizer shaft was $60 \mathrm{r} / \mathrm{min}$. Based on Equation (1), the fertilizer amount per lap of one distributor was $28.7 \mathrm{~g} / \mathrm{r}$.

Existing data ${ }^{[26]}$ shows that fertilizer amount per lap of the spiral fertilizer distributor can be calculated using Equation (2).

$$
q=\left[\pi\left(D^{2}-d^{2}\right) t / 4-Z b H L_{p}\right] \rho \varphi
$$

where, $q$ is the fertilizer amount per lap of the spiral fertilizer distributor, $\mathrm{g} / \mathrm{r} ; D$ is the outer diameter of the screw, $\mathrm{mm}$; $d$ is the inner diameter of the screw, $\mathrm{mm} ; t$ is the pitch of the screw, $\mathrm{mm} ; Z$ is the thread number; $B$ is the average thickness of the screw teeth, $\mathrm{mm} ; H$ is the depth of the screw thread, $H=(D-d) / 2, \mathrm{~mm} ; L_{p}$ is the average length of the screw thread, $\mathrm{mm} ; \rho$ is the fertilizer density, $\mathrm{g} / \mathrm{cm}^{3}$; and $\varphi$ is the filling coefficient of the spiral fertilizer distributor.

From the literature ${ }^{[27,28]}$, the density of a compound fertilizer is $1.861 \mathrm{~g} / \mathrm{cm}^{3}$ and the filling coefficient of a granular material is 0.40 . When $D=45 \mathrm{~mm}, t=30 \mathrm{~mm}, b=2 \mathrm{~mm}$, and $d=17 \mathrm{~mm}$, the theoretical fertilizer amount per lap was $q=28.32 \mathrm{~g} / \mathrm{r}$.

\section{Pneumatic fertilizer transporting system}

\subsection{General structure}

The pneumatic fertilizer transporting system determined whether the fertilizer could be smoothly transported to the fertilizer ditch. The structure employed in this research is shown in Figure 5.

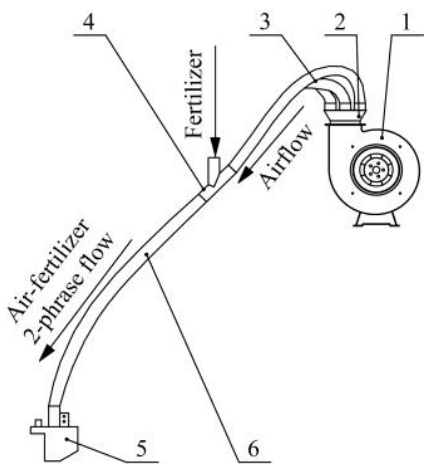

1. Centrifugal fan 2. Centralized airflow distribution device 3. Air pipe

4. Tee pipe 5. Furrow opener 6. Fertilizer pipe

Figure 5 Structure of the pneumatic fertilizer transporting system

\subsection{Air flow path optimization}

In the existing research on pneumatic fertilizer transporting, the method of placing fan one end of main air duct is mostly adopted, as shown in Figure 6a. To optimize the structure and working parameters of the pneumatic fertilizer transporting system, single-factor tests for the different airflow distribution methods (placing a fan at the end of the main air duct, placing a fan in the middle of the main air duct, and centralized airflow distribution) 
were carried out as shown in Figure 6. In addition, single-factor tests on the distance between openers and ground, which represented the curvature of fertilizer pipes, were carried out. The distances employed in the tests were set at 0,300 , and $600 \mathrm{~mm}$.

In the test, the fertilizer pipes used were PVC wire reinforced rubber hoses with $32 \mathrm{~mm}$ inner diameter. The fan was a 150FLJ7-type centrifugal fan with rated voltage of $220 \mathrm{~V}$, rated power of $330 \mathrm{~W}$, air volume of $660 \mathrm{~m}^{3} / \mathrm{h}$, and static pressure of
$450 \mathrm{~Pa}$. To measure the air speed of each branch at the end of airflow path, a E0-20KPA model Pitot tube anemometer with the scale interval of $0.01 \mathrm{~m} / \mathrm{s}$ was used in the test. When testing air speed of one branch at the end of its airflow path, the head of anemometer detector should be put in the center of opener inlet to obtain air speeds of different position. Then average air speed in different row would be calculated, which would be considered as the air speed of the branch. The results of the tests are shown in Figure 7.

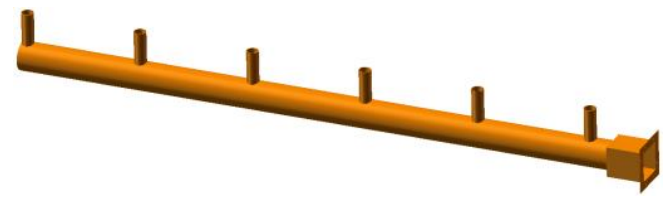

a. Placing a fan at the end of the main air duct

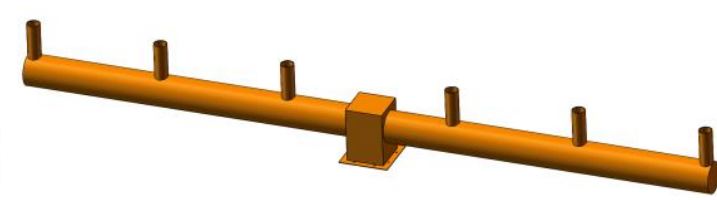

b. Placing a fan in the middle of the main air duct

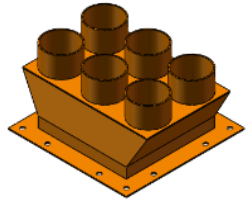

c. Centralized airflow distribution

Figure 6 Structures for the three different airflow distribution methods

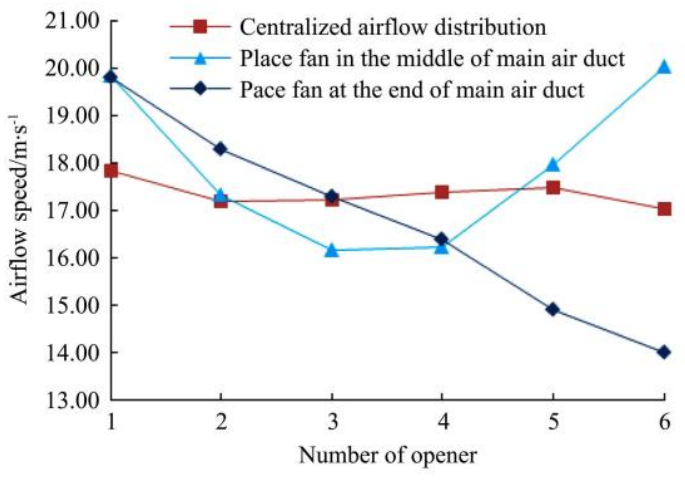

a. Influence of airflow distribution method

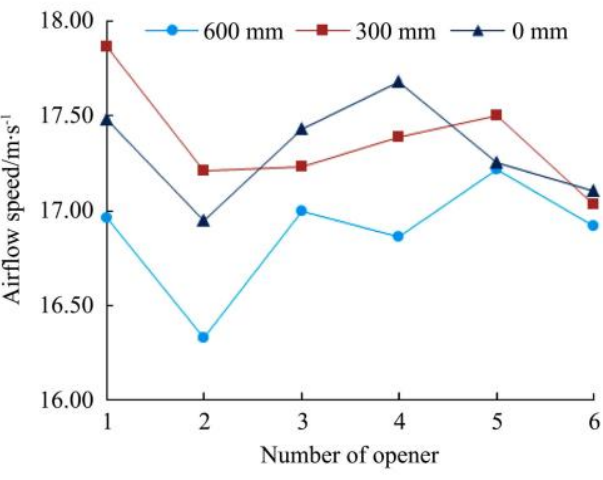

b. Influence of distance between openers and ground

Figure 7 Influence of the different factors on airflow velocity at each opener

The distance between openers and ground employed in the tests on airflow distribution method was set at $300 \mathrm{~mm}$. The variation coefficients of the airflow speed were $12.84 \%$ (Figure 6a), 9.49\% (Figure 6b), and 1.67\% (Figure 6c). Among the three methods, the centralized air distribution scheme had the best consistency of airflow speed at each branch. The airflow speed at each branch showed large difference when the fan was placed at the end or the middle of the main duct.

The tests on the factor of height between openers and the ground employed centralized airflow distribution. The results showed that there were differences in airflow speed, but the differences were not significant. When the distance between the opener and ground was $600 \mathrm{~mm}$, the difference of airflow speed at each branch was the greatest. At this condition, the range of airflow speed was $0.89 \mathrm{~m} / \mathrm{s}$ and the coefficient of variation of airflow speed consistency was $1.76 \%$. This indicates that the effect of the curvature of the fertilizer pipe on the consistency and average of the airflow speed at each branch was not obvious.

\section{Furrow opener system}

The structure of the ditcher system, including the opener fixing bracket and furrow opener, is shown in Figure 8. The bracket was installed on the cross beam of the planting device. The fertilization depth and the horizontal row distance between fertilizer and seedling could be adjusted by adjusting the bracket. The opener was mainly composed of the fertilizer inlet, fertilizer outlet, and opener body. The opener body was designed as a boat type, which could effectively break the soil in paddy field with a small resistance. In addition, straw and weeds in the paddy field could slide into the bottom and the bank of the fertilizer ditch along the outer surface of the opener body. During operation, the fertilizer enters through the inlet with the airflow. The airflow creates a pressure in the cavity of the openers, which prevents the slurry and water from going back into the pipe. This ensures that the fertilizer falls into the ditch smoothly.

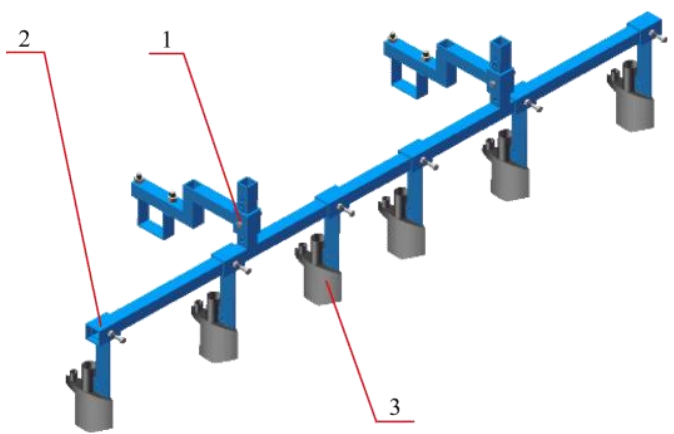

1. Fertilization depth adjusting device 2. Transverse fertilization position adjusting slider 3. Furrow opener

Figure 8 Structure of the opener system

\section{Control system}

\subsection{Hardware selection and design}

The hardware of the control system was mainly composed of the power supply module, signal acquisition module, main control module, DC motor drive module, and human-computer interaction module. The power module included $12 \mathrm{~V}$ battery for the motor drive module and $5 \mathrm{~V}$ USB DC power supply for the main control module. The signal acquisition module used a photoelectric sensor based on the H2010 opto-interrupter and LM393 dual voltage comparator, to measure the speed of the PTO and fertilizer shaft. The main control module used a Raspberry Pi 3B based on the Linux system. The motor drive module used an AQMD3615NS DC motor driving board based on the L298 
logic circuit. Human-computer interaction was achieved through handheld devices, such as notebooks or mobile phones with WIFI and remote desktop software. The hardware configuration is shown in Table 2 and the circuit diagram is shown in Figure 9.

To reduce fertilization error caused by insufficient precision of the forward speed measurement, this research used high-precision photoelectric sensor to detect high-frequency dark signals generated by circular grating disk installed on the PTO.
Table 2 Hardware of the fertilization control system

\begin{tabular}{lc}
\hline \multicolumn{1}{c}{ Components } & Model/main features \\
\hline Main control chip & Raspberry Pi 3B \\
Power supply for chip & USB on 5 V 2.1 A Power Bank \\
Photoelectric switch & H2010 opto-interrupter \\
Level signal converter & LM393 dual voltage comparator \\
DC motor driver & AQMD3615NS \\
Display & Via laptop or handheld devices with WIFI \\
\hline
\end{tabular}

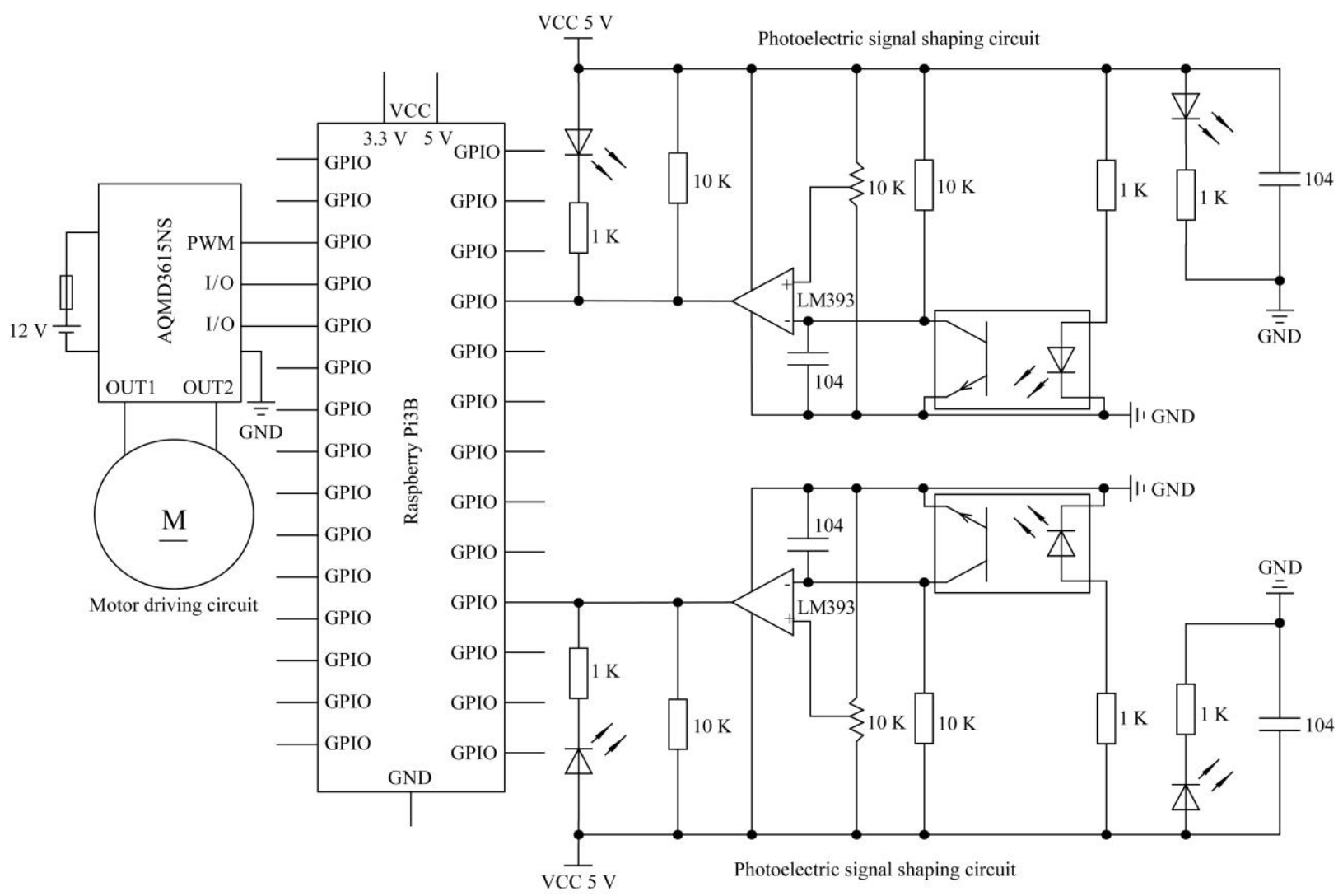

Figure 9 Circuit diagram of the fertilization control system

\subsection{Software design}

The control system software was designed in Python language environment. The schematic of the fertilization control system and main program flowchart are shown in Figures 10 and 11, respectively.

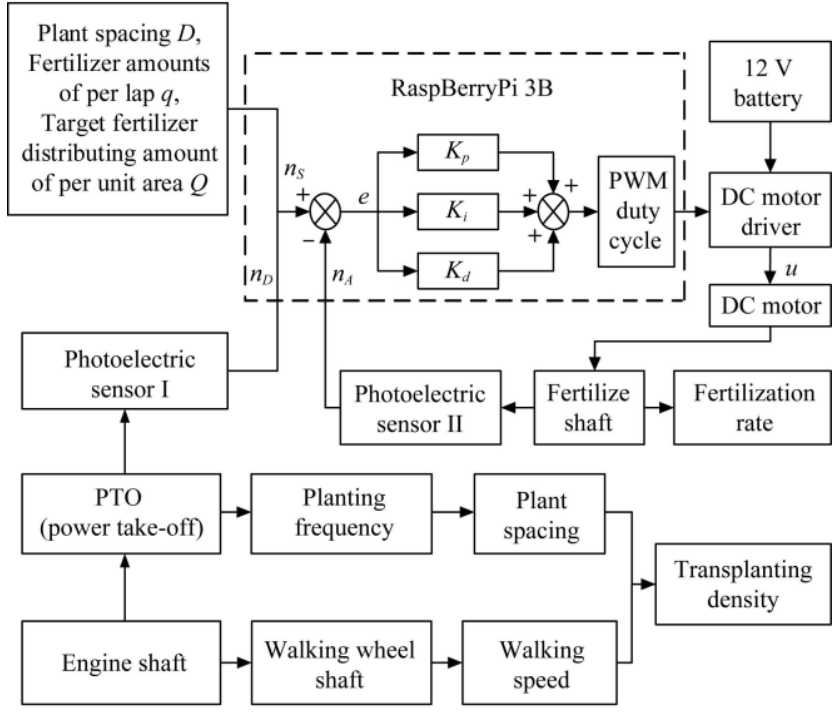

Figure 10 Schematic of the fertilization control system

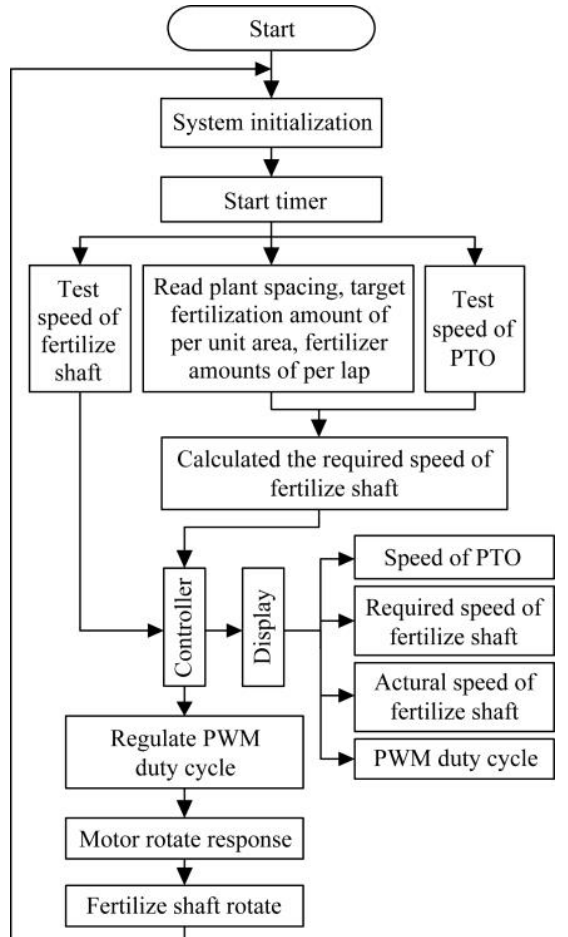

Figure 11 Flowchart of the main program 
The speed of the fertilizer discharger shaft was regulated using a PID closed-loop algorithm. Users can input parameters, such as plant spacing $D$, fertilizer amount per lap $q$, and target fertilizer distribution amount per unit area $Q$ using a keyboard. Raspberry Pi 3B obtained PTO speed $n_{D}$ through the photoelectric sensor I. The main program calculated the required speed of the fertilizer shaft $n_{S}$ using the aforementioned parameters and compared the calculated value with the actual speed $n_{A}$ measured by the photoelectric sensor II installed on fertilizer shaft. The speed difference $e=n_{S}-n_{A}$ was output to the PID algorithm. After running the PID algorithm, the PWM duty cycle was adjusted and sent to the motor driving board to control the speed of the DC motor accurately. The DC motor drove the fertilizer shaft and run with it to precisely control the fertilizer distribution rate.

During program debugging, it was found that the mechanical parts vibrated when the engine was started. This caused the photoelectric sensor on the fertilizer shaft occasionally detected abnormal high-frequency single pulse, which resulted in error when the speed of the fertilizer shaft was low causing the fertilizer shaft to run unsteadily or stop running. Thus, the sleeping vibration elimination method was used in the design of the fertilizer shaft speed measurement subprogram. When reading the rising edge,

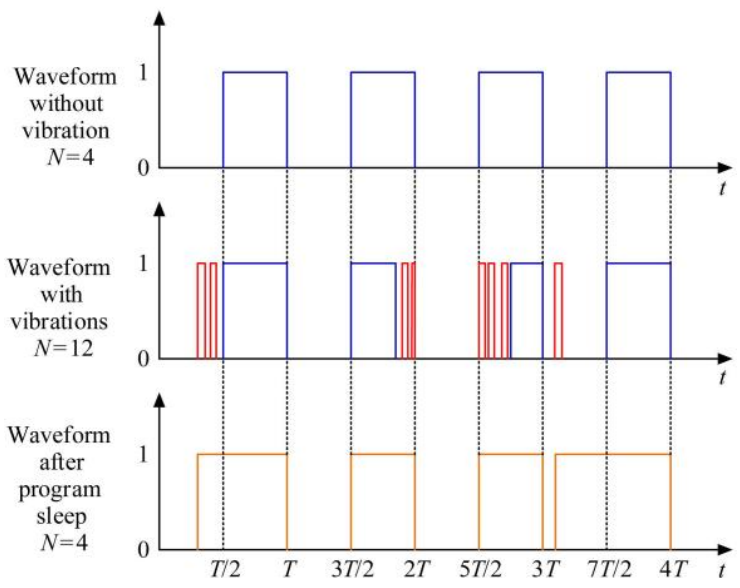

Figure 12 Principle of the sleeping vibration elimination

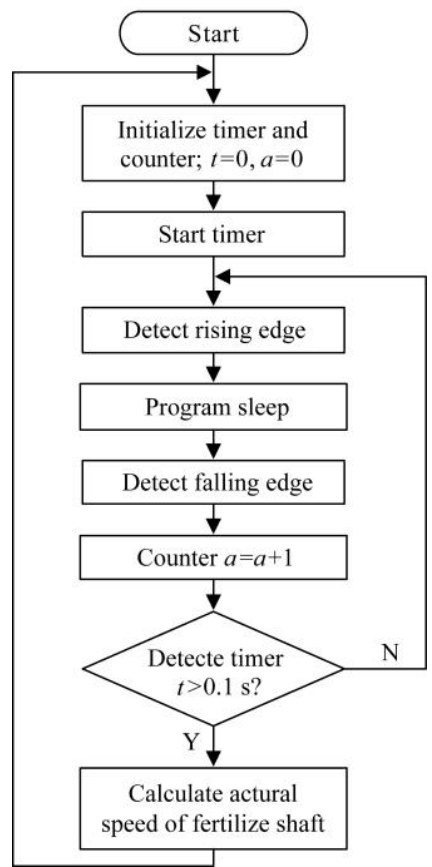

Figure 13 Flowchart of the fertilizer shaft speed measurement subprogram the falling edge should be read after a specific time $T / 2$ sleep (where $T$ is the signal period when there is no vibration interference) to reduce speed measurement error of the fertilizer shaft caused by mechanical vibration. The principle of sleeping vibration elimination is shown in Figure 12. After the program was set to sleep, the waveform changed, but the count remained constant or was changed slightly. The flowchart of the fertilizer shaft speed measurement subprogram is shown in Figure 13.

\section{Performance tests and results analysis}

\subsection{Bench tests of the fertilization system}

From March 20 to 24, 2019, bench tests were conducted at the Electromechanical Engineering Training Center of Huazhong Agricultural University to test the consistency of fertilization amount in different rows, the fertilization stability, and explore the effect of rotational speed of fertilizer shaft on fertilizer amount per lap in each distributor. During the test, sufficient amounts of fertilizer (Stanley compound fertilizer with bulk density of $0.872 \mathrm{~g} / \mathrm{cm}^{3}$ and moisture content of $6.5 \%$ ) were poured into six fertilizer boxes. Then, all the outlets of the openers were covered with nylon mesh bags with sufficient air permeability. The program was modified to run the fertilizer shaft at speeds of 10, 20, 30 , and $40 \mathrm{r} / \mathrm{min}$. The fertilization system was stopped after running it for a certain period. The working time was recorded and the fertilizer in each bag was collected and weighed. In the bench tests, each speed was tested five times.

The fertilizer amount per lap of each distributor was calculated using the following formula:

$$
q_{i k}=\frac{60 \cdot m_{i k}}{n_{k} \cdot t_{k}}
$$

where, $q_{i k}$ is the fertilizer amount per lap of the $i$-th row in the $k$-th test, $\mathrm{g} / \mathrm{r} ; m_{i k}$ is the fertilizer mass of the $i$-th row in the $k$-th test, $\mathrm{g}$; $n_{k}$ is the fertilizer shaft speed of the $k$-th test, $\mathrm{r} / \mathrm{min}$; and $t_{k}$ is the working time of the $k$-th test, s.

7.1.1 Coefficient of variation of fertilization consistency in different rows

According to the trade standard "NY/T 1003-2006 Technical specifications of quality evaluation for fertilizing machinery", the coefficient of variation of fertilizer consistency in different rows was calculated using Equation (4). And the variation coefficient of fertilization consistency in different rows should be less than $13 \%{ }^{[29]}$.

$$
\left\{\begin{array}{l}
q=\frac{\sum_{i=1}^{n} q_{i}}{n} \\
S=\sqrt{\frac{\sum_{i=1}^{n}\left(q_{i}-q\right)^{2}}{n-1}} \\
V=\frac{S}{q} \times 100
\end{array}\right.
$$

where, $q_{i}$ is the average fertilizer amount per lap of each test in different rows $(i=1,2,3 \ldots, 6), \mathrm{g} / \mathrm{r} ; q$ is the average value of the fertilizer amount per lap of each test in each fertilizer distributor, $\mathrm{g} / \mathrm{r} ; S$ is the standard deviation of the fertilizer consistency in different rows, $\mathrm{g} / \mathrm{r}$; and $V$ is the coefficient of variation of the fertilizer consistency in different rows, $\%$.

\subsubsection{Coefficient variation of fertilization stability}

Also, the standard defines that the variance coefficient of fertilization stability has equation similar to Equation (4); however, in its equation, $q_{i}$ is sum of fertilizer amount per lap of each test $(i=$ 
$1,2,3 \ldots, 5), \mathrm{g} / \mathrm{r} ; q$ is average of the sum of the fertilizer amount per lap of each test, $\mathrm{g} / \mathrm{r} ; S$ is standard deviation of fertilization stability, $\mathrm{g} / \mathrm{r}$; and $V$ is variation coefficient of the fertilization stability, \%. And the variation coefficient of fertilization stability should be less than $7.8 \%^{[29]}$.

\subsubsection{Test results}

In the bench tests, the rotational speed of the fertilizer shaft was set at 10, 20,30, and $40 \mathrm{r} / \mathrm{min}$. The results of the fertilizer consistency in different rows are shown in Figure 14a. It shows that the maximum coefficient of variation of the fertilization consistency in different rows was $1.49 \%$ at the rotational speed of $20 \mathrm{r} / \mathrm{min}$. The results of the fertilization stability are shown in Figure 14b. The maximum coefficient of variation of the fertilization stability was $2.86 \%$ at the rotational speed of $40 \mathrm{r} / \mathrm{min}$. The average fertilizer amount per lap of each distributor was 27.28 , 26.63, 26.26, and $24.82 \mathrm{~g} / \mathrm{r}$. The average fertilizer amount per lap of each distributor for the four speeds was $26.25 \mathrm{~g} / \mathrm{r}$. The coefficient of variation for the influence of rotational speed on the average fertilizer amount per lap was $3.97 \%$. This indicates that the difference between each fertilizer distributor was small, the fertilization stability of the device was good, and the effect of rotational speed on fertilizer amount per lap was also small.

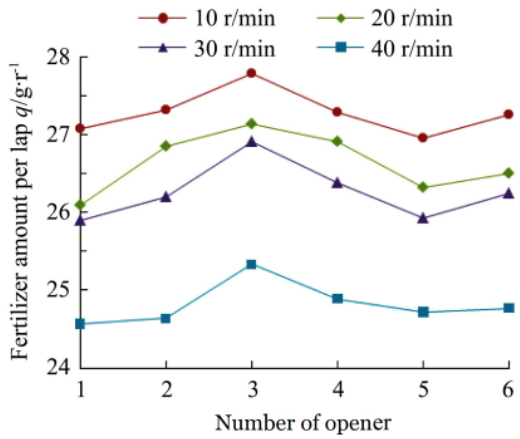

a. Average fertilizer amount per lap in different rows at different speed

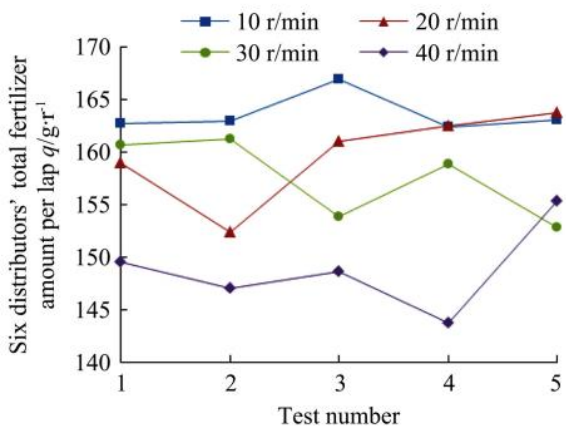

b. Six distributors' total fertilizer amount per lap in each test at different speed

Figure 14 Bench test results of fertilization system

\subsection{Dynamic fertilization tests}

To test the accuracy of the fertilizer distribution system when the transplanter was moving forward and the fertilizer amount per unit area was appointed, dynamic fertilizer distribution tests were conducted on a hard road at Huazhong Agricultural University from March 25 to 26, 2019. The fertilizer used was similar to the ones used in the bench tests. During the test, a plastic film (20.25 $\mathrm{m}$ long and $2 \mathrm{~m}$ wide) was first laid on the road. And the height between openers and ground was set to $80 \mathrm{~mm}$. Then the machine was driven through the plastic film to apply fertilizer on it. Then, the fertilizer scattered on the plastic film was collected and weighted to represent the actual amount of the fertilizer. The actual fertilizer amount was compared with the theoretical fertilizer amount to calculate the fertilizer distribution accuracy of the system.

The theoretical fertilizer amount collected from the plastic film was estimated as follows:

$$
M=\frac{1000 \cdot Q}{667} \cdot S=1.5 Q S
$$

where, $M$ is the theoretical fertilizer amount on the plastic film, $g$; $S=1.8 L$ is the working area of the transplanter, $\mathrm{m}^{2} ; Q$ is the target fertilizer amount per unit area, $\mathrm{kg} / 667 \mathrm{~m}^{2}$.

The dynamic fertilization test is shown in Figure 15. During the test, the fertilizer amount per unit area $Q$ was set at 20,30, and $40 \mathrm{~kg} / 667 \mathrm{~m}^{2}$. Each test was repeated four times. The results showed that the relative errors of the average fertilizer amount for the abovementioned fertilizer amounts per unit area were $1.81 \%$, $0.15 \%$, and $2.00 \%$, respectively.

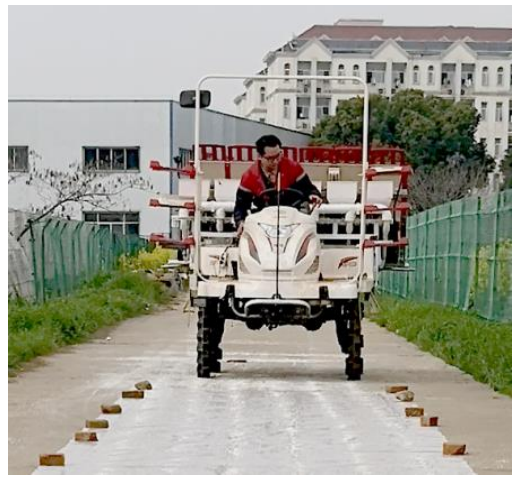

Figure 15 Dynamic fertilization tests

\subsection{Field tests}

To test the performance of the fertilizer distribution system in practical working conditions, field tests were conducted in Siwumen Village, Wulin Town, Honghu City, Hubei Province from April 27 to 28, 2019. The total working area was $4659.2 \mathrm{~m}^{2}$. The fertilizer used in the experiment was a compound fertilizer (N-P-K content of 26-10-15, bulk density of $0.816 \mathrm{~g} / \mathrm{cm}^{3}$, and moisture content of $3.07 \%$ ). The fertilizer amount per lap was about $23 \mathrm{~g} / \mathrm{r}$, and the seedling used in the test was super hybrid rice Fengliangyouxiang 1 . The openers were set to $50 \mathrm{~mm}$ under the ground, according to the agronomic requirements of fertilization in rice planting. Field tests condition is shown in Figure 16.

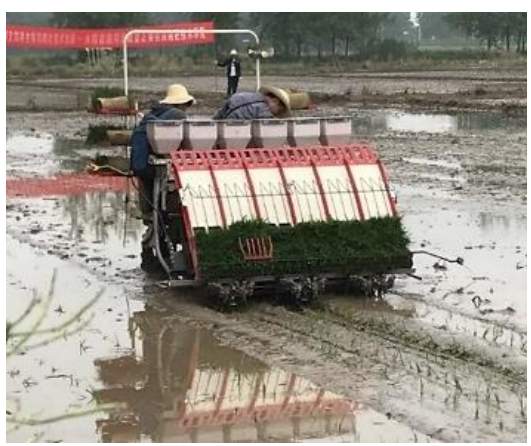

Figure 16 Field tests of the rice transplanting and fertilizing machine

After the tests, the theoretical fertilization amount $M_{i}$ for each area was calculated using Equation (5) and the total relative error of the fertilization amount was calculated using Equation (6). And as the standard required, the total relative error of fertilization amount should be less than $15 \%{ }^{[29]}$.

$$
\gamma_{s}=\frac{W_{0}-W_{1}-\sum \frac{M_{i}}{1000}}{\sum \frac{M_{i}}{1000}} \times 100 \%
$$


where, $\gamma_{s}$ is the total relative error of the fertilizer amount, \%; $W_{0}$ is the total fertilizer amount added during the test, $\mathrm{kg} ; W_{1}$ is the fertilizer amount remaining in the fertilizer box after the test, kg; and $M_{i}$ is the theoretical fertilization amount for each area, g.

The results of field tests are shown in Table 3. It shows that the total relative error between the theoretical and actual fertilization amount was $3.53 \%$, which met the design standard.

Table 3 Results of the field tests

\begin{tabular}{lccc}
\multicolumn{1}{c}{ Area number } & 1 & 2 & Sum \\
\hline Working area $S / \mathrm{m}^{2}$ & 604.8 & 4054.4 & 4659.2 \\
Target fertilizer amount per unit area $Q$ & 20 & 30 & \\
$/ \mathrm{kg}$ per $667 \mathrm{~m}^{2}$ & 18.13 & 182.36 & 200.49 \\
Theoretical fertilizer amount $M_{i} / \mathrm{kg}$ & - & - & 207.57 \\
Actual fertilizer amount $W / \mathrm{kg}$ & - & - & 3.53 \\
Relative error $\gamma_{s} / \%$ & &
\end{tabular}

\section{Conclusions}

(1) A six-row centralized pneumatic rice deep precision fertilization device for transplanter was designed, which consisted of a spiral fertilizer distribution system, pneumatic fertilizer transporting system, furrow opener system, and fertilization control system. The centralized airflow distribution method was adopted to ensure uniform and consistent airflow in each fertilizer pipe. Photoelectric sensors were used to measure the rotational speed of PTO and fertilizer shaft. Two speeds were matched proportionately in real-time using PID closed-loop control algorithms to achieve precise fertilization rate at each working speed of the rice transplanter. To reduce measurement errors caused by mechanical vibration, a sleeping vibration elimination program was added to the fertilizer shaft speed detection subprogram to ensure precise control of the fertilization amount.

(2) In the bench tests, the rotational speed of the fertilizer shaft was set at 10, 20,30, and $40 \mathrm{r} / \mathrm{min}$. The results show that the maximum coefficient of variation of the fertilizer consistency in different rows was $1.49 \%$ at the rotational speed of $20 \mathrm{r} / \mathrm{min}$, the maximum coefficient of variation of the fertilization stability was $2.86 \%$ at the rotational speed of $40 \mathrm{r} / \mathrm{min}$, and the average fertilizer amount per lap of each distributor was $26.25 \mathrm{~g} / \mathrm{r}$. The results of the dynamic fertilization tests show that the maximum relative error of the fertilizer distribution amount was $2.00 \%$ when the target fertilizer rate was set at 20,30 , and $40 \mathrm{~kg} / 667 \mathrm{~m}^{2}$ even if the transplanter had an unsteady forward speed.

(3) Field experiments were conducted. The results show that the total relative error between theoretical and actual fertilization amounts was $3.53 \%$, which met the design standard.

\section{Acknowledgements}

This research was supported by the National Key Research and Development Project of China (2017YFD0301404-05) and the Fundamental Research Funds for the Central Universities (2662018PY038).

\section{[References]}

[1] Wang W N, Lu J W, Chen F, Lu M X, Li H, Li X K. Study on fertilization effect and fertilizer use efficiency of rice in Hubei Province. Plant Nutrition and Fertilizer Science, 2010; 16(2): 289-295. (in Chinese)

[2] Wang X H, Liu J, Wang Y Q. Soil nitrogen transport characteristics under different fertilizer application practice. Chinese Journal of Soil Science, 2002; 33(3): 202-206. (in Chinese)

[3] Chen X F, Luo X W, Wang Z M, Zhang M H, Hu L, Zeng S, et al.
Experiment of synchronous side deep fertilizing technique with rice hill-drop drilling. Transactions of the CSAE, 2014; 30(16), 1-7. (in Chinese)

[4] Pan S G, Mo Z W, Luo X W, Wang Z M, Tian H, Duan M Y, et al. Effects of deeply mechanized fertilizer application on the quality and grain yield of direct seedling rice. Journal of Huazhong Agricultural University, 2013; 32(2): 1-5. (in Chinese)

[5] Shu S F, Tang X R, Luo X W, Li G X, Wang Z M, Zheng T X, et a1 Effects of deep mechanized application of slow-release fertilizers on physiological characteristics of precision hill-direct-seeding super rice. Transactions of the CSAE, 2011; 27(3): 89-92. (in Chinese)

[6] Jin X, Li Q W, Yuan Y W, Qiu Z M, Zhou L M, He Z T. Design and test of 2BFJ-24 type variable fertilizer and wheat precision seed sowing machine. Transactions of the CSAM, 2018; 49(5): 91-99. (in Chinese)

[7] Wang T S, Feng X J, Liu Y Q, Zhang H F. The study on 2BJT-2 universa precise seeder. Transactions of the CSAM, 1996; 27(S1): 80-84. (in Chinese)

[8] Zen S, Tang H T, Luo X W, Ma G H, Wang Z M, Zang Y, et al. Design and experiment of precision rice hill-drop drilling machine for dry land with synchronous fertilizing. Transactions of the CSAE, 2012; 28(20): 12-19. (in Chinese)

[9] Zhai J B, Xia J F, Zhou J H, Zhou Y, Zhan P C. Design and field trials of pneumatic precision drilling planter of rice budded seed in dry land. Journal of Huazhong Agricultural University, 2017; 36(1): 116-122. (in Chinese)

[10] Qi X Y, Zhou Z Y, Yang C, Luo X W, Gu X Y, Zang Y, et al. Design and experiment of key parts of pneumatic variable-rate fertilizer applicator for rice production. Transactions of the CSAE, 2016; 32(6): 20-26. (in Chinese)

[11] Wang J W, Li S W, Zhang Z, Li Q C. Design and experiment of electrical drive side deep hill-drop fertilization system for precision rice hill-direct-seeding machine. Transactions of the CSAE, 2018; 34(8): 43-54. (in Chinese)

[12] Chen X F, Wang Z M, Luo X W, Zhang M H, Hu L, Zeng S, et al. Design and experiment of synchronous side deep fertilizing with rice hill-drop drilling of 2BDF-3.0 machinery. Journal of Shenyang Agricultural University, 2018; 49(3): 309-314. (in Chinese)

[13] Wang J F, Gao G B, Weng W X, Wang J W, Yan D W, Chen B W. Design and experiment of key components of side deep fertilization device for paddy field. Transactions of the CSAM, 2018(6): 92-104. (in Chinese)

[14] Wang J F, Gao G B, Wang J W, Yan D W. Design and test of adjustable blades side deep fertilizing device for paddy field. Transactions of the CSAM, 2018; 49(3): 68- 76. (in Chinese)

[15] Zuo X J, Wu G W, Fu W Q, Li L W, Wei X L, Zhao C J. Design and experiment on air-blast rice side deep precision fertilization device. Transactions of the CSAE, 2016; 32(3): 14-21. (in Chinese)

[16] Chen C H, Xu C L, Bi C H, Li M J, Wu J A, Zhang X D. Researching of rice transplanter deep side fertilizing technology and device. Journal of Heilongjiang Bayi Agricultural University, 2012; 24(6): 10-12. (in Chinese)

[17] Nakamura N, Nakagawa Y, Shimizu T. Fertilizer applicator. China Patent No. CN103583126A, 2014. (in Chinese)

[18] Kato T. Fertilizer applicator. Japan Patent No. JP6237575B2, 2017.

[19] Oomae K. Fertilizer applicator and riding-type rice transplanter having same mounted thereon. Japan Patent No. WO2011/055693A1, 2011.

[20] Wang S P, Di X J, Hu J H, Song S M. Rice transplanter fertilization device and rice transplanter. China Patent No. CN107223394A, 2017. (in Chinese)

[21] Ye Y W, Wang Y G. Lateral-deep rice fertilizer distributor and method China Patent No. CN106612808A, 2017. (in Chinese)

[22] Chen L Q, Xie B B, Li Z D, Yang L, Chen Y X. Design of control system of maize precision seeding based on double closed loop PID fuzzy algorithm. Transactions of the CSAE, 2018; 34(9): 33-41. (in Chinese)

[23] Meng Z J, Zhao C J, Liu H, Huang W Q, Fu W Q, Wang X. Development and performance assessment of map-based variable rate granule application system. Journal of Jiangsu University: Natural Science Editions, 2009; 30(4): 338-342. (in Chinese)

[24] Zhang C L, Wu R, Chen L Q. Design and test of electronic control seeding system for maize. Transactions of the CSAM, 2017; 48(2): 51-59. (in Chinese)

[25] Ye Y W, Wang Y G. Rice side deep fertilizing machine. China Patent No. CN206602814U, 2017. (in Chinese)

[26] Chen X F, Luo X W, Wang Z M, Zhang M H, Hu L, Yang W W, et al. 
Design and experiment of fertilizer distribution apparatus with double-level screws. Transactions of the CSAE, 2015; 31(3): 10-16. (in Chinese)

[27] Dun G Q, Chen H T, Feng Y N, Yang J L, Li A, Zha S H. Parameter optimization and test of key parts of fertilizer allocation device based on EDEM software. Transactions of the CSAE, 2016; 32(7): 36-42. (in Chinese)
[28] Dong X H, Liu G, Zhou W Y, Wang J L, Lü X, Gao Z W. Design of spiral auger material discharging device. Agricultural Science \& Technology and Equipment, 2014; 1: 33-34. (in Chinese)

[29] NY/T 1003-2006. Technical specifications of quality evaluation for fertilizing machinery. China: Ministry of Agriculture of the People's Republic of China. (in Chinese) 